\title{
RELIGIUSITAS INTRINSIK, RELIGIUSITAS EKSTRINSIK, DAN NIAT UNTUK MENGHINDARI PAJAK
}

Amir Hidayatulloh ${ }^{1}$

amir.hidayatulloh@act.uad.ac.id

Akuntansi, Universitas Ahmad Dahlan

Muhammad Nur Syamsu ${ }^{2}$

muhammadnursyamsu9@gmail.com

Akuntansi, Universitas Ahmad Dahlan

\begin{abstract}
Abstrak
Populasi dalam penelitian ini adalah wajib pajak orang pribadi di seluruh Indonesia. Teknik pengambilan sampel dalam penelitian menggunakan purposive samping, dengan kriteria wajib pajak orang pribadi yang memiliki NPWP. Teknik pengumpulan data dalam penelitian menggunakan metode survei, dengan menyebar kuesioner kepada responden dengan bantuan google form. Responden dalam penelitian ini sebesar 128 responden yang berasal dari 25 propinsi. Teknik analisis data dalam penelitian ini menggunakan analisis regresi linear berganda. penelitian ini memperoleh hasil bahwa religiusitas intrinsik dan religiusitas ekstrinsik berpengaruh terhadap niat untuk menghindari pajak.
\end{abstract}

Kata Kunci: Penghindaran Pajak, Religiusitas Intrinsik, Religiusitas Ekstrinsik

\section{INTRINSIC RELIGIOSITY, EKTRINSIC RELIGIOSITY AND INTENTION TO AVOID TAX}

\section{Abstract}

The population in this study are individual taxpayers throughout Indonesia. The sampling technique in the study used purposive sampling, with criteria of individual taxpayer who have NPWP. Data collection techniques in this study used the survey method, by questionnaire to respondents with help to google form. Respondents in this study were 128 respondents from 25 provinces. The data analysis technique in this study used multiple linear regression. This study obtained result that intrinsic religiosity and extrinsic religiosity influence the intention to avoid taxes.

Keywords: Tax Avoidance, Intrinsic Religiosity, Extrinsic Religiosity

\section{PENDAHULUAN}

Pajak merupakan sumber terbesar pendapatan Negara. Menurut Direktur Potensi dan Kepatuhan Penerimaan Pajak Yon Arsal yang dikutip dari(Kementerian keuangan Indonesia, 2016)bahwa realisasi penerimaan pajak pada tahun 2018 belum sesuai dengan target yang telah ditetapkan. Hal ini diketahui pada akhir November 2018 realisasi penerimaan pajak sudah mencapai Rp 1.136,66 triliun atau 79,82 persen dari target yang ditetapkan APBN sebesar Rp 1.422 triliun.

Selaku pegawai KPP Pratama Jakarta Kebayoran Lama yang dikutip dalam pada laman (Indonesia, 2016), mengatakan kasus penghindaran pajak dalam sepuluh tahun terakhir menjadi 
fokus dari otoritas perpajakan internasional. Masalah ini muncul adanya kejadian pada tahun 2008, yaitu adanya krisis global yang melanda negara Indonesia sehingga menyebabkan banyak negara mengalami kesulitan dalam mencari sumber pendapatan.

Menurut (Mardiasmo, 2016) mengatakan bahwa penghindaran pajak merupakan perilaku yang tidak melanggar undang-undang serta memiliki tujuan untuk meringankan beban pajak. Ada berbagai cara yang dilakukan para pelaku pajak untuk melakukan tindakan penghindaran pajak (tax avoidance). Salah satunya dengan menggunakan segala cara tanpa memperhatikan etis atau tidaknya cara tersebut demi mendapatkan apa yang inginkan.

Menurut (Utama \& Wahyudi, 2016)mengatakan bahwa beberapa peneliti luar negeri menemukan bahwa religiusitas berpengaruh terhadap perilaku kepatuhan Wajib Pajak. Religiusitas yang dimiliki setiap orang memiliki tingkatan yang berbeda-beda. Religiusitas seseorang berasal dari dua faktor yang memengaruhi yakni berasal dari faktor intrinsik maupun faktor ekstrinsik (Allport \& Ross, 1967).

Penelitian ini terinspirasi dari penelitian terdahulu, yaitu penelitian(Budiarto, Yennisa, \& Nurmalisa, 2017). Pada penelitian terdahulu, peneliti mencoba untuk menguji religiusitas dan machiavellian seseorang dengan penggelapan pajak (tax evasion). Serta objek yang digunakan adalah mahasiswa yang ada di Daerah Istimewa Yogyakarta. Pada penelitian ini, terdapat perbedaan dengan penelitian terdahulu. Penelitian ini ingin menguji apakah terdapat pengaruh religiusitas intrinsik, dan religiusitas ekstrinsik terhadap niat untuk menghindari pajak, serta objek dalam penelitian ini adalah Wajib Pajak Orang Pribadi (WPOP).

Alasan peneliti menggunakan objek wajib pajak orang pribadi dibandingkan dengan mahasiswa karena wajib pajak orang pribadi telah memiliki kewajiban untuk membayar pajak yang telah diatur pada undang-undang perpajakan. Sedangkan, mahasiswa hanya sebatas memiliki perspektif mengenai pajak dan belum berperan secara langsung dalam aktivitas membayar pajak.

\section{Penghindaran Pajak}

\section{KAJIAN PUSTAKA}

Menurut (Mardiasmo, 2016) mengatakan terdapat dua hambatan dalam pemungutan pajak yaitu perlawanan pasif dan perlawanan aktif. Perlawanan pasif adalah suatu perlawanan yang dilakukan oleh wajib pajak untuk enggan (pasif) dalam membayar pajak, yang dapat disebabkan karena perkembangan moral dan dan intelektual masyarakat, sistem perpajakan yang kemungkinan sulit untuk dipahami dan sistem pengendali yang tidak dapat dilakukan atau dilaksanakan dengan baik. Sedangkan perlawanan aktif meliputi semua usaha dan tindakan yang dilakukan oleh wajib pajak dengan tujuan untuk menghindari pajak, yang meliputi penghindaran pajak dan penggelapan pajak.

Penghindaran pajak merupakan suatu usaha untuk meringankan beban pajak dengan tidak melanggar undang-undang yang berlaku di negara tersebut. Sedangkan, penggelapan pajak adalah suatu usaha untuk meringankan beban pajak dengan cara melanggaran undang-undang yang berlaku di negara tersebut.

Selain itu, pembeda antara penghindaran pajakdan penggelapan pajakadalah legalitas diantara keduannya. Penghindaran pajak bersifat legal dan penggelapan bersifat illegal. Praktik pengelompokkan diantara keduanya tergantung pada interpretasi otoritas pajak yang ada di masing-masing negara. Sehingga dapat disimpulkan, hal yang membedakan antara penghindaran pajak dan penggelapan pajak adalah dari sisi legalitasnya. Sedangkan dari sisi etis, kedua praktik ini sebenarnya bertentangan dengan maksud dari undang-undang (Suryowati, 2016). 
Seseorang yang ingin melakukan penghindaran pajak tidak lepas dari dorongan dalam diri setiap individu. Niat merupakan salah satu faktor yang menyebabkan individu melakukan penghindaran pajak. Triandis (1980) dalam (Wanarta \& Mangoting, 2014), mengatakan bahwa niat merupakan suatu instruksi yang muncul dari dalam diri seorang individu itu sendiri guna untuk melakukan suatu perilaku tertentu.

\section{Religiusitas}

Menurut(McDaniel \& Burnett, 1990), religiosity adalah keyakinan terhadap Sang Pencipta dengan mempunyai komitmen untuk mengikuti aturan-aturan dan ajaran-ajaran yang telah ditetapkan-Nya. Religiusitas dapat diartikan sebagai kepercayaan, aktivitas ritual, gaya hidup serta memberikan sebuah arti dalam keberlangsungan kehidupan manusia dan mengantarkan manusia kepada nilai-nilai tertinggi maupun nilai-nilai suci (Glock dan Stark, 1965) dalam(Budiarto et al., 2017).

Menurut (Allport \& Ross, 1967), religiusitas dibedakan menjadi religiusitas intrinsik dan religiusitas ekstrinsik. Lebih lanjut, (Allport \& Ross, 1967)mengatakan bahwa Religiusitas yang berasal dari intrinsik menunjukkan bahwa keyakinan dipikirkan secara seksama serta harus dilaksanakan secara sungguh-sungguh. Seseorang dengan religiusitas intrinsik akan menjunjung tinggi nilai-nilai keagamaan. Agama dalam orientasi intrinsik dapat memberikan petunjuk dalam menjalani hidup. Orang yang memiliki religiusitas intrinsik mampu menerima kritikan dengan baik, hidup percaya diri serta percaya mampu mengatasi sebuah masalah yang ada dalam kehidupan, karena hidup orang tersebut berpegang pada prinsip dan agama yang orang tersebut anut. (Allport \& Ross, 1967)mengatakan religiusitas ekstrinsik digunakan individu untuk mencapai tujuan dalam beragama. Pribadi yang mempunyai religiusitas ekstrinsik akan bereaksi bila ada faktor eksternal duniawi yang mempengaruhi dirinya.

Menurut (Allport \& Ross, 1967) menjelaskan bahwa setiap individu yang memiliki orientasi religiusitas ekstrinsik akan memandang agama dalam berbagai hal, diantaranya untuk memperoleh pembenaran diri, penghiburan, rasa aman, dan bertahan melawan realita atau memberi sanksi pada suatu cara hidup. Bagi setiap individu, kepercayaan yang dianutnya cenderung dilambangkan secara selektif agar cocok dengan kebutuhan yang bersifat primer.

\section{RERANGKA PEMIKIRAN DAN PENGEMBANGAN HIPOTESIS}

Rerangka penelitian ini dibuat untuk memudahkan pemahaman mengenai apakah terdapat pengaruh religiusitas intrinsik, danreligiusitas ekstrinsik terhadap niat untuk menghindari pajak. Sesuai dengan penelitian ini, maka rerangka penelitian disajikan pada gambar 1.

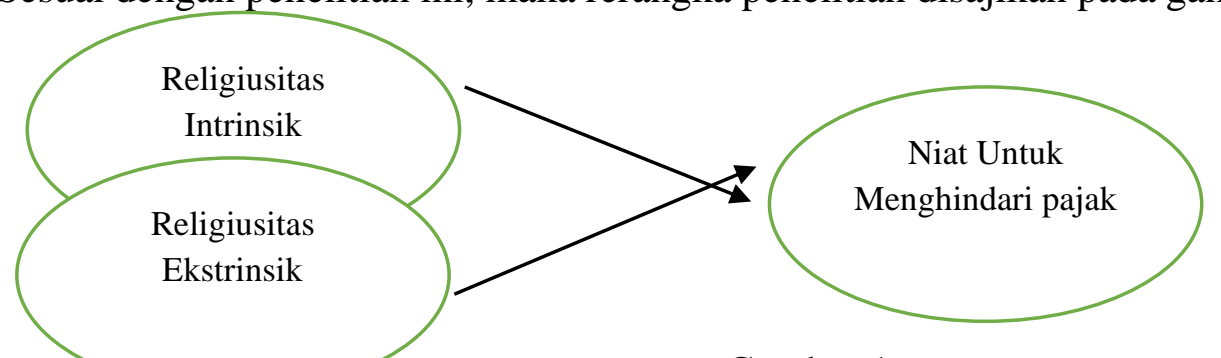

Gambar 1

Rerangka Penelitian

\section{Religiusitas Intrinsik terhadap Niat Untuk Menghindari Pajak}

Menurut Allport (1950) dalam(Hafizhah, 2016), seorang individu yang memiliki religiusitas intrinsik merupakan seseorang yang menjadikan agamanya sebagai tujuan dalam menjalani hidup. Individu yang memiliki religiusitas intrinsik ini akan menjadikan agamanya 
sebagai sebuah tolak ukur dalam melangsungkan hidup dengan menginternalisasi sebuah nilainilai dari kepercayaan agamanya dalam setiap melakukan perbuatan sehari-hari.

Berdasarkan prespektif agama, perilaku dalam hal kecurangan pajak dianggap tidak beretika. Individu dengan orientasi religiusitas intrinsik akan beranggapan bahwa kecurangan pajak itu selalu tidak etis walaupun dengan berbagai alasan yang diberikan (Hafizhah, 2016). (Singhapakdi, Vitell, Lee, Nisius, \& Yu, 2013) menemukan hasil bahwa religiusitas intrinsik berpengaruh terhadap niat etis. Oleh karena itu adapun hipotesis yang diambil dalam penelitian ini adalah:

$\mathrm{H}_{1}$ : Religiusitas intrinsik berpengaruh terhadap niat untuk menghindari pajak

\section{Religiusitas Ekstrinsik terhadap Niat Untuk Menghindari Pajak}

Allport (1950) dalam (Hafizhah, 2016), mengatakan bahwa religiusitas ekstrinsik memberikan gambaran peranan agama dari luar sebagai dukungan sosial dalam menjalani hidup. Seseorang yang mempunyai religiusitas ekstrinsik akan memanfaatkan agamanya sebagai suatu alat yang digunakan untuk memenuhi kepentingan pribadinya. Seseorang yang memiliki kepribadian ini akan lebih termotivasi jika ada sesuatu yang menguntungkan dalam hal duniawi. Penelitian yang dilakukan oleh (Singhapakdi et al., 2013)menemukan hasil bahwa religiusitas esktrinsik berpengaruh terhadap niat etis. Oleh sebab itu, hipotesis yang terbentuk dalam penelitian ini adalah:

$\mathrm{H}_{2}$ : Religiusitas ekstrinsik berpengaruh terhadap niat untuk menghindari pajak

\section{METODE PENELITIAN}

Populasi dalam penelitian ini adalah Wajib Pajak Orang Pribadidi seluruh Indonesia. Teknik pengambilan sampel dilakukan dengan menggunakan purposive sampling. Adapun kriteria yang dilihat, yaitu Wajib Pajak Orang Pribadi (WPOP) yang memiliki Nomor Pokok Wajib Pajak (NPWP). Data penelitian ini diperoleh melalui penyebaran kuesioner kepada wajib pajak orang pribadi yang memiliki NPWP dengan bantuan google form.

Variabel penelitian ini terdiri dari variabel independen (religiusitas intrinsik dan religiusitas ekstrinsik), serta variabel dependen (kepatuhan wajib pajak). Definisi operasional dan pengukuran variabel disajikan pada tabel 1 . Teknik analisis data dalam penelitian ini menggunakan analisis regresi linear berganda.

Niat untuk menghindari pajak merupakan perilaku yang tidak melanggar undang-undang serta memiliki tujuan untuk meringankan beban pajak (Mardiasmo, 2016). Niat untuk menghindari pajak diukur dengan menggunakan lima belas pernyataan yang diadopsi dari (Budiarto et al., 2017), dan menggunakan skala likert lima point, yaitu sangat tidak setuju (STS), tidak setuju (TS), netral (N), setuju (S), dan sangat setuju (SS).

Menurut (Allport \& Ross, 1967), religiusitas intrinsik merupakan kemurnian hati, visi, serta pengertian tentang makna dalam ritual-ritual keagamaan harus di junjung tinggi. Religiusitas intrinsik diukur dengan menggunakan dua belas item pertanyaan yang diadopsi (Budiarto et al., 2017), dan menggunakan skala likert lima point, yaitu sangat tidak setuju (STS), tidak setuju (TS), netral (N), setuju (S), dan sangat setuju (SS).

Religiusitas ektrinsik merupakan agama digunakan untuk mencapai tujuan masing-masing setiap individu (Allport \& Ross, 1967). Religiusitas ekstrinsik diukur dengan menggunakan delapan item pernyataan yang diadopsi dari (Budiarto et al., 2017), dan menggunakan skala likert lima point, yaitu sangat tidak setuju (STS), tidak setuju (TS), netral (N), setuju (S), dan sangat setuju (SS).

\section{Gambaran Umum Objek Penelitian}

\section{HASIL DAN PEMBAHASAN}


Populasi penelitian ini adalah seluruh wajib pajak orang pribadi yang ada di Indonesia. Adapun teknik pengambilan sampel pada penelitian ini menggunakan purposive sampling, dengan kriteria wajib pajak orang pribadi yang ada di indonesia dan memiliki Nomor Pokok Wajib pajak (NPWP). Sampel dalam penelitian ini adalah wajib pajak orang pribadi yang ada di Indonesia serta mempunyai NPWP. Pengambilan data dilakukan dalam jangka waktu satu bulan (Bulan April).

Tabel 2

Sampel dan Tingkat Pengambilan

\begin{tabular}{ccccc}
\hline Responden & $\begin{array}{c}\text { Kuesioner Yang } \\
\text { Terisi }\end{array}$ & $\begin{array}{c}\text { Kuesioner Yang } \\
\text { Tidak Sesuai } \\
\text { Kriteria }\end{array}$ & $\begin{array}{c}\text { Kuesioner Yang } \\
\text { Tidak Konsisten }\end{array}$ & $\begin{array}{c}\text { Kuesioner Yang } \\
\text { Diolah }\end{array}$ \\
\hline $\begin{array}{c}\text { Seluruh Wajib } \\
\text { Pajak Orang } \\
\text { Pribadi yang ber } \\
\text { NPWP di }\end{array}$ & 201 & 23 & 50 & 128 \\
Indonesia & & & & \\
\hline
\end{tabular}

Sumber: Data Primer, diolah (2019)

Berdasarkan tabel 2 dapat dijelaskan bahwa jumlah kuesioner yang terisi dengan mengggunakan google form pada penelitian ini sebanyak 201 kuesioner. Kuesioner yang tidak sesuai kriteria berjumlah 23 kuesioner, serta kuesioner yang tidak dapat diolah karena tidak konsisten dalam mengisi berjumlah 50 kuesioner. Jadi, total kuesioner yang di uji pada penelitian ini berjumlah 128 kuesioner

\section{Deskripsi Responden}

Deskripsi responden dalam penelitian ini meliputi domisili, jenis kelamin, usia dan tingkat pendidikan. Deskripsi responden disajikan pada tabel 3.

Tabel 3

Deskripsi Responden

\begin{tabular}{|c|c|c|c|}
\hline Data Deskriptif & Keterangan & Jumlah & Presentase \\
\hline \multirow{21}{*}{ Domisili } & DIY & 49 & $38 \%$ \\
\hline & Sulawesi Tengah & 15 & $11,71 \%$ \\
\hline & Jawa Tengah & 6 & $4,68 \%$ \\
\hline & DKI Jakarta & 6 & $4,68 \%$ \\
\hline & Jawa Barat & 5 & $3,90 \%$ \\
\hline & NTB & 5 & $3,90 \%$ \\
\hline & Sumatera Utara & 5 & $3,90 \%$ \\
\hline & Banten & 4 & $3,13 \%$ \\
\hline & Kalimantan Tengah & 4 & $3,13 \%$ \\
\hline & Kalimantan Timur & 3 & $2,34 \%$ \\
\hline & Sulawesi Selatan & 3 & $2,34 \%$ \\
\hline & Bangka Belitung & 3 & $2,34 \%$ \\
\hline & Kepulauan Riau & 3 & $2,34 \%$ \\
\hline & Kalimantan Selatan & 2 & $1,56 \%$ \\
\hline & Bali & 2 & $1,56 \%$ \\
\hline & Sulawesi Utara & 2 & $1,56 \%$ \\
\hline & Maluku Utara & 2 & $1,56 \%$ \\
\hline & Jawa Timur & 2 & $1,56 \%$ \\
\hline & Riau & 1 & $0,78 \%$ \\
\hline & Sumatera Selatan & 1 & $0,78 \%$ \\
\hline & Lampung & 1 & $0,78 \%$ \\
\hline
\end{tabular}




$\begin{array}{cccc} & \text { Kalimantan Utara } & 1 & 0,78 \% \\ & \text { Sulawesi Tenggara } & 1 & 0,78 \% \\ & \text { Maluku } & 1 & 0,78 \% \\ \text { Papua } & 1 & 0,78 \% \\ \text { Lenis Kelamin } & \text { Perempuan } & 77 & 60,16 \% \\ & \text { Antara 20-25 Tahun } & 51 & 39,84 \% \\ & \text { Antara 26-30 Tahun } & 17 & 13,28 \% \\ & \text { Antara 31-35 Tahun } & 13 & 7,81 \% \\ & \text { Antara 36-40 Tahun } & 19 & 10,16 \% \\ & \text { Antara 41-45 Tahun } & 3 & 14,84 \% \\ & \text { Diatas 45 Tahun } & 66 & 2,34 \% \\ & \text { SD } & - & 51,56 \% \\ \text { Singkat Pendidikan } & \text { SMA } & - & - \\ & \text { D1/D2/D3 } & 17 & - \\ & \text { S1/S2/S3 } & 7 & 13,28 \% \\ & & 104 & 8,47 \% \\ & & \end{array}$

Sumber: Data primer, diolah (2019)

Berdasarkan tabel 3 deskripsi responden dalam penelitian ini terdiri dari domisili, jenis kelamin, usia dan tingkat pendidikan. Jumlah responden dalam penelitian ini berasal dari 25 Provinsi yang ada di seluruh Indonesia. Responden yang berjenis kelamin laki-laki pada penelitian ini sebesar $(60,16 \%)$, sedangkan responden berjenis kelamin perempuan pada penelitian ini sebesar $(39,84 \%)$. Selain itu jika dilihat dari usianya, responden yang memiliki usia dikisaran 20-25 tahun sebesar (13,28\%), responden yang memiliki usia antara 26-30 tahun sebesar (7,81\%), responden yang memiliki usia 31-35 tahun sebesar (10,16\%), responden yang memiliki usia 36-40 tahun sebesar (14,84\%), responden yang memiliki usia 40-45 tahun sebesar $(2,34 \%)$, dan responden yang memiliki usia 45 tahun ke atas sebesar (51,56\%). Selanjutnya, berdasarkan tingkat pendidikannya diketahui responden yang memiliki tingkat pendidikan SMA sebesar $(13,28 \%)$, responden yang memiliki tingkat pendidikan D1/D2/D3 sebesar $(5,47 \%)$ dan responden yang memiliki tingkat pendidikan S1/S2/S3 sebesar $(81,25 \%)$.

\section{UJI HIPOTESIS}

Uji hipotesis dalam penelitian ini terdiri dari koefisien determinasi $\left(\mathrm{R}^{2}\right)$, uji simultan $(\mathrm{F})$ dan uji parsial (t). Hasil uji hipotesis pada penelitian ini disajikan pada tabel 4.

\section{Tabel 4}

Hasil Pengujian Analsis Regresi Berganda

\begin{tabular}{lcccc}
\hline \multicolumn{1}{c}{ Variabel } & Koefisien & Signifikansi & Alpha & Keputusan \\
\hline \multicolumn{1}{c}{ Religiusitas Intrinsik } & 0,133 & 0,000 & 0,05 & $\mathrm{H}_{1}$ terdukung \\
Religiusitas Ekstrinsik & 0,157 & 0,040 & 0,05 & $\mathrm{H}_{2}$ terdukung \\
& & & & \\
\hline Konstanta & $=19.697$ & & & \\
Variabel dependen & $=$ Penghindaran Pajak & & & \\
Adjusted R Square & $=0,265$ & & & \\
F Statistik & $=23.867$ & & & \\
Signifikansi & $=0,000$ & & & \\
\hline
\end{tabular}

Sumber: Data primer, diolah (2019)

Berdasarkan pada tabel 4 nilai koefisien determinasi (Adjusted $\mathrm{R}^{2}$ ) diperoleh 0,265. Nilai koefisien determinasi sebesar 26,5\%, artinya variabel penghindaran pajak dipengaruhi oleh variabel religiusitas intrinsik dan religiusitas ekstrinsik. Sedangkan sisanya $73,5 \%$ dijelaskan oleh variabel lain yang tidak digunakan dalam penelitian ini. 
Tabel 4 menunjukan hasil uji simultan (Uji F) dapat diperoleh tingkat signifikan 0,000 yang lebih kecil dari nilai alpha 0,05 . Jadi pada penelitian ini diketahui bahwa minimal terdapat satu variabel independen yang terdiri atas religiusitas intrinsik dan religiusitas ekstrinsik memiliki pengaruh terhadap penghindaran pajak.

Tabel 4 menunjukan bahwa menunjukkan bahwa variabel religiusitas intrinsik berpengaruh terhadap variabel penghindaran pajak. Hal ini dapat dilihat dari nilai signifikansi $(0,000)$ yang lebih kecil dibandingkan 0,05. Atau dengan kata lain, hipotesis pertama $\left(\mathrm{H}_{1}\right)$ penelitian ini terdukung. Hasil ini mendukung hasil penelitian sebelumnya (Budiarto et al., 2017); (Singhapakdi et al., 2013) yang menyatakan bahwa religiusitas intrinsik berpengaruh terhadap niat etis. Hal ini berarti bahwa sikap intrinsik yang ada dalam diri setiap individu dapat mengendalikan setiap perbuatan yang dilakukan. Individu dengan orientasi religiusitas intrinsik akan memberikan sebuah anggapan bahwa aktivitas kecurangan pajak merupakan tindakan yang tidak etis untuk dilakukan (Hafizhah, 2016).

Hasil penelitian ini mendukung penelitian sebelumnya, (Wati \& Sudibyo, 2017), religiusitas mempunyai pengaruh terhadap presepsi etis. Artinya semakin rendah religiusitas setiap individu maka semakin besar kemungkinan akan melakukan kecurangan pajak. Penelitian yang dilakukan oleh (Utama \& Wahyudi, 2016) juga menemukan hasil bahwa semakin tinggi religiusitas seseorang maka akan semakin tinggi tingkat kepatuhan pajaknya.

Kepatuhan wajib pajak dipengaruhi oleh religiusitas ektrinsik. Hal dapat dilihat dari nilai signifikasi $(0,040)$ yang lebih kecil dibandingkan dengan 0,05. Atau dengan kata lain, hipotesis kedua $\left(\mathrm{H}_{2}\right)$ penelitian ini terdukung. Hasil penelitian ini mengkonfirmasi hasil penelitian sebelumnya (Singhapakdi et al., 2013), bahwa religiusitas esktrinsik berpengaruh terhadap niat etis.Hal ini berarti bahwa wajib pajak yang memiliki sikap religiusitas tinggi cenderung untuk berperilaku etis dan menghindari kecurangan pajak. Artinya, apabila tingkat religiusitas wajib pajak rendah maka besar kemungkinan wajib pajak tersebut akan melakukan penghindaran pajak (Grasmick, Kinsey, \& Cochran, 1991).

\section{SIMPULAN}

Niat untuk menghindari pajak dipengaruhi oleh religisuitas intrinsik dan religiusitas ekstrinsik. Hal ini berarti bahwa sikap intrinsik yang ada pada diri individu dapat mengendalikan setiap perbuatan yang dilakukan. Individu yang memiliki orientasi religiusitas intrinsik akan memberikan sebuah anggapan bahwa aktivitas kecurangan pajak merupakan tindakan yang tidak etis untuk dilakukan. Begitu juga, ketika individu memiliki religiusitas ekstrinsik maka individu akan lebih termotivasi jika ada sesuatu yang menguntungkan dalam hal duniawi. Sehingga, ketika individu tersebut menganggap bahwa membayar pajak bagi dirinya menguntungkan, maka individu tersebut akan bersikap patuh.

Penelitian ini memiliki nilai adjusted $r$ square sebesar 0,265. Sehingga, variabel independen (religiusitas intrinsik dan religiusitas ekstrinsik) dapat menjelaskan variabel kepatuhan wajib pajak 26,5\%. Sehingga 73,5\% kepatuhan wajib pajak dijelaskan oleh variabel lain di luar model. Sehingga, penelitian selanjutnya dapat menambahkan variabel independen seperti sanksi perpajakan, tarif pajak, pengetahuan pajak, maupun sikap fiskus. Selain itu, penelitian ini menggunakan metode pengumpulan data menggunakan kuesioner. Sehingga, seperti yang melekat pada keterbatasan penggunaan metode survei yaitu validitas internal rendah, maka penelitian selanjutnya dapat menggunakan metode wawancara agar memperoleh validitas internal yang tinggi. 


\section{DAFTAR PUSTAKA}

Allport, G. W., \& Ross, J. M. (1967). Personal Religious Orientation and Prejudice. Journal of Personality and Social Psychology, 5(4), 432-443.

Budiarto, S. D., Yennisa, \& Nurmalisa, F. (2017). Hubungan Antara Religiusitas dan Machiavellian dengan Tax Evasion: Riset Berdasarkan Prespektif Gender. Jurnal Telaah Bisnis, 18(1), 19-32.

Grasmick, H. G., Kinsey, K., \& Cochran, J. K. (1991). Denomination, Religiosity and Compliance with the Law: A Study of Adults. Journal for the Scientific Study of Religion, 30(1), 99. https://doi.org/10.2307/1387152

Hafizhah, I. (2016). Faculty of Economics Riau University, Pekanbaru Indonesia. Pengaruh Etika Uang Terhadap Kecuranagan Pajak Dengan Religiusitas, Gender Dan Materialisme Sebagai Variabel Moderasi, 2(2), 2010-2012.

Indonesia, K. K. R. (2016). Menkeu Nilai Tingkat Kepatuhan Wajib Pajak Indonesia Masih Rendah.

Mardiasmo. (2016). Perpajakan (2016th ed.). CV Andi.

McDaniel, S.W ., \& Burnett, J.J. (1990). Consumer Religiosity and Retail Store Evaluative Criteria. Journal of the Academy of Marketing Science, 18(2), 101-112.

Singhapakdi, A., Vitell, S. J., Lee, D. J., Nisius, A. M., \& Yu, G. B. (2013). The Influence of Love of Money and Religiosity on Ethical Decision-Making in Marketing. Journal of Business Ethics, 114(1), 183-191. https://doi.org/10.1007/s10551-012-1334-2

Suryowati, E. (2016). Apa Perbedaan Praktik Penghindaran Pajak dan Penggelapan Pajak?

Utama, A., \& Wahyudi, D. (2016). Pengaruh Religiusitas terhadap Perilaku Kepatuhan Wajib Pajak Orang Pribadi di Provinsi DKI Jakarta. Jurnal Lingkar Widyaiswara, 3(2), 1-13. https://doi.org/10.1016/S0040-4020(00)00446-4

Wanarta, F. E., \& Mangoting, Y. (2014). Pengaruh Sikap Ketidakpatuhan Pajak, Norma Subjektif, dan Kontrol Perilaku yang Dipersepsikan terhadap Niat Wajib Pajak Orang Pribadi untuk Melakukan Penggelapan Pajak. Tax \& Accounting Review, 4(1), 138. Retrieved from http://publication.petra.ac.id/index.php/akuntansi-pajak/article/view/3112

Wati, M., \& Sudibyo, B. (2017). Pengaruh Pendidikan Etika Bisnis Dan Religiusitas Terhadap Persepsi Etis Mahasiswa Akuntansi. Jurnal Economia, 12(2), 183. https://doi.org/10.21831/economia.v12i2.11775

Copyright (c) 2020 Amir Hidayatulloh, Muhammad Nur Syamsu 